
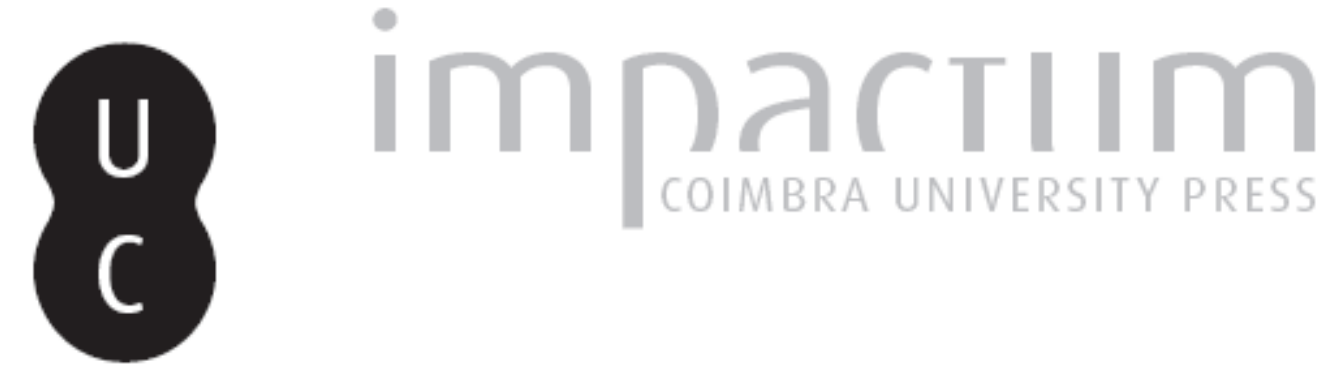

Riscos associados à exploração mineira: o caso das minas da Panasqueira

Autor(es): $\quad$ Gonçalves, Anselmo Casimiro Ramos

Publicado por: Faculdade de Letras da Universidade de Coimbra, Departamento de Geografia

URL $\quad$ URI:http://hdl.handle.net/10316.2/30211

DOI: $\quad$ DOl:http://dx.doi.org/10.14195/0871-1623_31_12

Accessed : $\quad$ 26-Apr-2023 15:20:55

A navegação consulta e descarregamento dos títulos inseridos nas Bibliotecas Digitais UC Digitalis, UC Pombalina e UC Impactum, pressupõem a aceitação plena e sem reservas dos Termos e Condições de Uso destas Bibliotecas Digitais, disponíveis em https://digitalis.uc.pt/pt-pt/termos.

Conforme exposto nos referidos Termos e Condições de Uso, o descarregamento de títulos de acesso restrito requer uma licença válida de autorização devendo o utilizador aceder ao(s) documento(s) a partir de um endereço de IP da instituição detentora da supramencionada licença.

Ao utilizador é apenas permitido o descarregamento para uso pessoal, pelo que o emprego do(s) título(s) descarregado(s) para outro fim, designadamente comercial, carece de autorização do respetivo autor ou editor da obra.

Na medida em que todas as obras da UC Digitalis se encontram protegidas pelo Código do Direito de Autor e Direitos Conexos e demais legislação aplicável, toda a cópia, parcial ou total, deste documento, nos casos em que é legalmente admitida, deverá conter ou fazer-se acompanhar por este aviso.

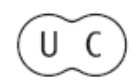




\title{
Riscos associados à exploração mineira. 0 caso das minas da Panasqueira
}

\author{
Anselmo Casimiro Ramos Gonçalves \\ Departamento de Geografia e Centro de Estudos de Geografia e Ordenamento do Território (CEGOT). Faculdade de Letras da Universidade de Coimbra. \\ Anselgoncalves@gmail.com
}

\section{Resumo:}

Refletir sobre os riscos associados à actividade mineira (externos e internos, riscos para a saúde e acidentes de trabalho) não pode ser visto de modo algum com alarmismo, mas sim como uma atitude de consciencialização das populações, das entidades municipais e estatais responsáveis pela gestão do risco, assim como das próprias empresas mineiras.

Palavras-chave: Riscos externos, internos. Saúde. Acidentes de trabalho.

\section{Résumé:}

Risques associés à l'exploitation minière. De la panasqueira mine affaire.

Réfléchir sur les risques associés aux activités minières (externes et internes, des risques pour la santé et les accidents de travail) ne peut en aucun cas être interprétée d'une façon alarmiste, mais comme une attitude de sensibilisation des collectivités, des municipalités et des entités de l'État responsables de la gestion du risque, ainsi que les entreprises minières elles-mêmes.

Mots clés: Risques externe, interne, pour la santé. Accidents du travail.

\section{Abstract:}

Risks associated with mining. The Panasqueira mine case.

To reflect about the risks associated to the mining activity (external and internal, health risks and work accidents), it can't be understood with panic, in any way, but as an attitude of awareness of population, of municipal and state entities, responsible by the risk management, as well as of the mining companies themselves.

Keywords: External, internal, health risks. Accidents at work.

Introdução

A extração mineral é uma de muitas atividades humanas que têm contribuído nos últimos cem anos para a degradação ambiental, quer do local onde se encontram instaladas, quer por vezes, da região envolvente.

$\mathrm{Na}$ verdade, a procura do minério e da sua eventual utilização por parte do Homem remonta a períodos anteriores à ocupação romana, havendo registos de exploração de óxidos de ferro na Suazilândia à 40.000 A.C., tendo desempenhado desde essa altura um papel essencial na sua sobrevivência, e porque não, no seu progresso (Roque, 2009).

$\mathrm{Na}$ actividade mineira e, em particular, na subterrânea, são muitos os riscos presentes e estes, estão associados às características do material rochoso perfu- rado, uso de explosivos, eventual presença de gases tóxicos, presença de águas subterrâneas, emprego cada vez maior de máquinas e equipamentos, possibilidade de ocorrência de incêndios, todos eles fazem parte do espectro alargado de riscos com o qual todos os mineiros e comunidades envolventes convivem diariamente.

\section{Os riscos associados à exploração mineira}

$\mathrm{Na}$ indústria mineira o risco é definido como uma característica física ou química de um material, processo ou instalação que tem o potencial de causar danos às pessoas e ao ambiente (PINO, 2002).

Certo será dizer que a indústria mineira hoje tem uma preocupação crescente com os acidentes externos 
e internos ocorridos na exploração, o que a leva a produzir estudos de avaliação de riscos de forma a poder detetar os chamados pontos fracos ao nível do funcionamento das instalações, assim como no processo extrativo que inclui as explosões, como dos danos provocados ao ambiente.

\subsection{Deslizamentos em escombreiras}

As modificações na morfologia, a perda de solo, a alteração da qualidade da água, a inevitável perda de vegetação e as modificações na rede de drenagem causadas pela exploração e aliadas às escombreiras ou mesmo às galerias subterrâneas podem induzir, nas zonas envolventes, um aumento do risco de desprendimentos, deslizamentos dos taludes (fotografia 1), assim como abatimento de terrenos (subsidências) e aumento da carga sólida dos cursos de água, com assoreamentos e consequentes inundações. Segundo LADEIRA, in FAVA, (1999: 98) "os movimentos de massa embora dependentes de factores externos como a precipitação, estão no entanto condicionados pelas características geológicas e geotécnicas inerentes à escombreira, o que torna este tipo de movimentos um assunto privilegiado na questão da estabilidade destas". Independentemente de existirem inúmeras classificações para este tipo de movimentos, apresentamos de seguida aqueles que nos parecem ser os que apresentam um maior significado para a estabilidade / instabilidade de taludes de escombreiras.

As formas de instabilidade (Figura 1) em escombreiras, são apresentadas pelo ITGE (1989, p. 33) e po-

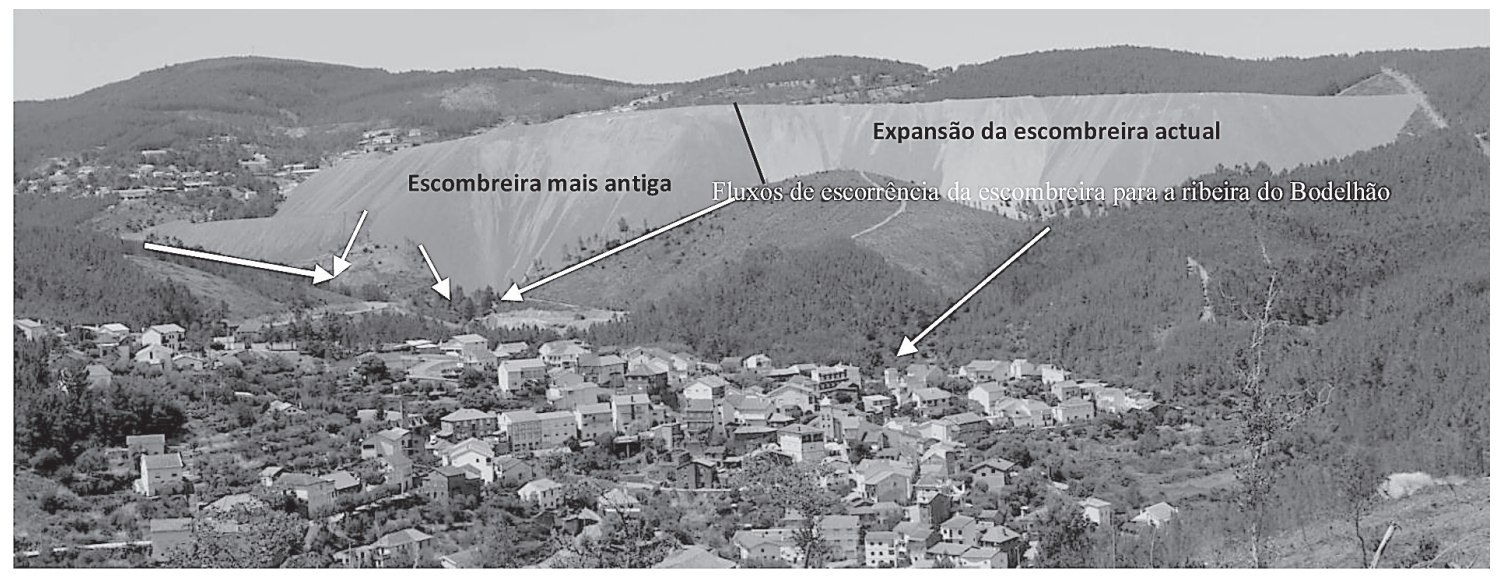

Fotografia 1

Desenvolvimento da escombreira ativa seguindo o método do despejo livre. Em primeiro plano a aldeia de S. Francisco de Assi (Fotografia do autor, 2011).

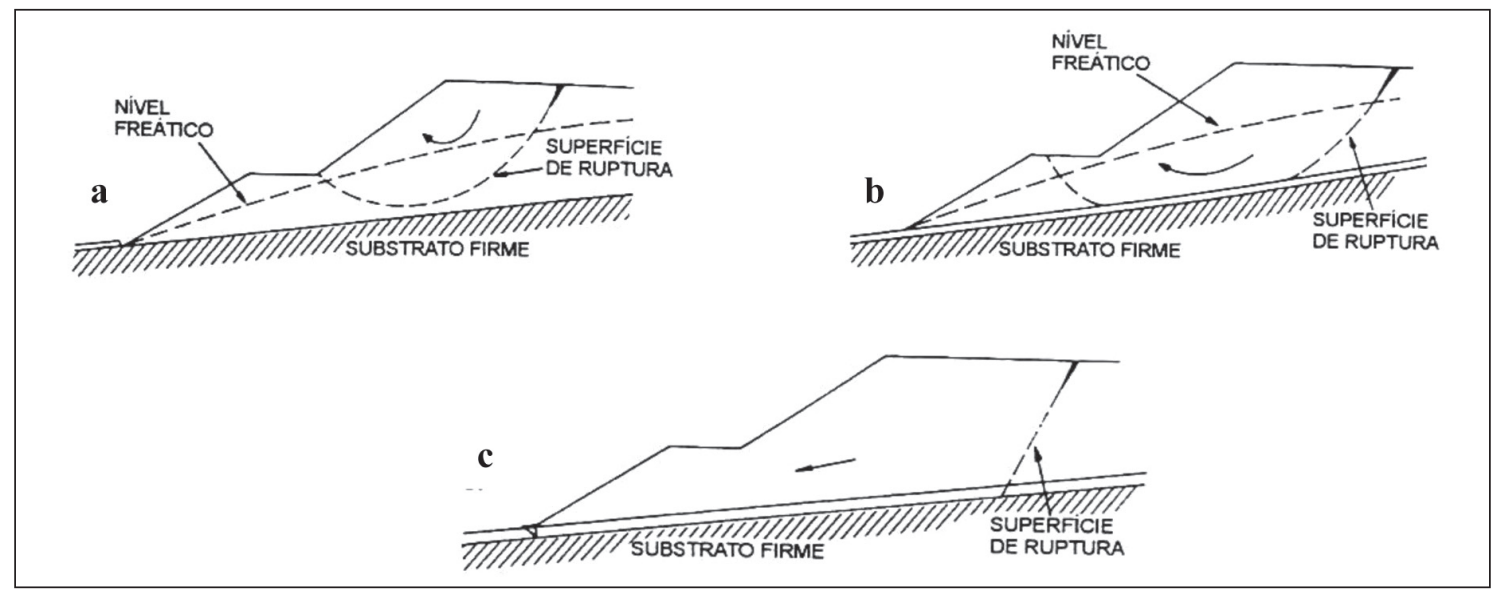

Figura 1

Principais tipos de roturas em escombreiras de acordo com a geometria: a) rotacional; b) mista; c) translacional (Figura retirada de ITGE, 1989: 33). 
dem classificar-se tendo em conta a posição da superfície de rotura em:

- Superficiais, quando não afectam a base da escombreira;

- Profundas, sempre que atingem a base da escombreira.

Podemos identificar os tipos de rotura de acordo com a geometria das mesmas. Assim temos:

a) Deslizamentos rotacionais (circulares) - próprios de materiais com granulometria fina e com propriedades geotécnicas homogéneas; por regra adopta-se um arco de circunferência para a superfície de escorregamento;

b) Deslizamentos mistos - trata-se de movimentos bastante complexos geralmente associados a escorregamentos rotacionais que incluem componentes translacionais e ou do tipo fluxo na sua base;

c) Deslizamentos translacionais (cunha) - próprios dos materiais com fortes anisotropias, estas roturas ocorrem através de um plano; é um tipo de movimento que poderá ocorrer quando a base de apoio da escombreira não é suficientemente resistente para suportar o peso dos estéreis.

As minas da Panasqueira, têm, neste momento, duas áreas encerradas (Panasqueira e Cabeço do Pião). Após o encerramento destas deveriam ter sido feitos estudos de avaliação de riscos o que à época (1965 e 1994, respetivamente), não nos parece ter sido a principal preocupação da empresa. Esses estudos deveriam ter sido realizados de forma a identificar as vulnerabilidades que poderiam surgir após o encerramento da mina, tais como:

- Instabilidade de escombreiras, que se traduz geralmente em movimentos de vários tipos (creep, deslizamentos, desenvolvimento de ravinas, etc., Fotografia 2), condicionados por diversos factores intrínsecos (tipo de material e granulometria, variações de temperatura e humidade, queda intensa de precipitação, seja em curtos períodos de tempo ou em períodos mais dilatados, efeito de vibrações, mecanismos erosivos, etc.), e que pode ter consequências gravosas para pessoas e equipamentos, obstrução de vias de comunicação, assoreamento de rios e, por vezes, em função da quantidade do material deslizado poderá este bloquear provisoriamente a totalidade do curso de água, funcionando como barragem, criando aqui a acumulação de água a montan- te ${ }^{1}$. São normalmente casos como este que as sumem um aspecto mais catastrófico pois o efeito momentâneo de barragem ao ser removido, favorece o aparecimento de uma nova frente destruidora de água e lama, eventualmente contaminada por metais pesados que invariavelmente vão inviabilizar a prática da agricultura por um largo período de tempo nos campos atingidos pela enxurrada (GUIDICINI; NIEBLE, 1983).

- Queda de material das escombreiras em áreas próximas de caminhos.

Depois de ocorrer o abandono da mina os problemas de instabilidade tendem a agravar-se devido ao elevado grau de degradação das estruturas de suporte estabelecidas durante a exploração, constituindo um factor de duplo risco para a segurança de pessoas, bens e animais das zonas limítrofes (Fotografia 2).

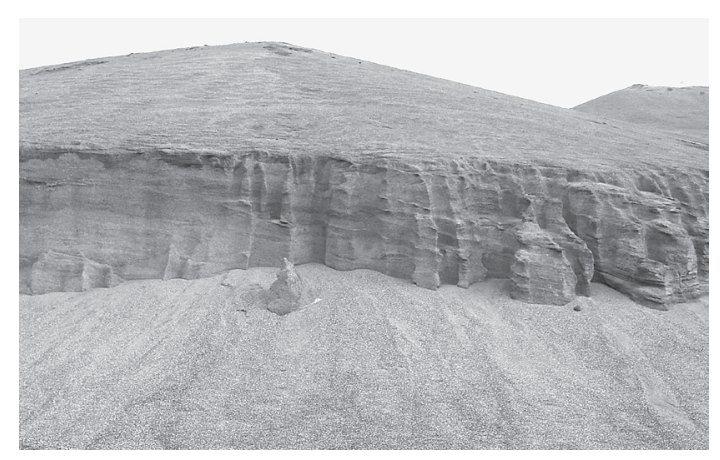

Fotografia 2

Cicatriz de uma secção de rotura vertical na escombreira do Cabeço do Pião, junto à barragem de lamas nas proximidades do rio Zêzere (Fotografia do autor).

\section{Efeitos da atividade mineira sobre os solos e as águas}

Um dos riscos ambientais mais preocupantes, tem a ver com as escombreiras e, resultam ou resultaram duma intensa atividade mineira que contribuiu para a contaminação (por metais pesados, substâncias utilizadas no tratamento do minério, etc.) dos sistemas ambientais que envolvem a respetiva escombreira.

${ }^{1}$ Situação similar foi-nos relatada por alguns idosos residentes em S. Jorge da Beira, como tendo acontecido durante a segunda guerra mundial, tendo nessa altura falecido algumas mulheres que estavam a lavar minério e foram apanhadas ou pelo deslizamento de terras, ou pela acção posterior da água represada, que entretanto rebentou o bloqueio efetuado pelas terras que deslizaram e que se acumularam no leito da ribeira de Cebola. Tentámos confirmar tal situação junto da empresa BTWP no entanto, não existem registos desta ocorrência. 
A contaminação por metais é particularmente importante nos casos em que ocorrem drenagens ácidas a partir de sulfuretos depositados na escombreira. A drenagem destas águas ácidas para as linhas de água, provoca a dispersão dos metais e a contaminação e acidificação das águas superficiais e dos solos. Segundo RuBIO, 1986, in FAVA (1999: 172-173), "As águas afetadas por DAM (drenagens ácidas de minas), de um modo geral não são potáveis, apresentando teores elevados de diversas substâncias, nomeadamente de metais pesados, que condicionam o seu uso, quer doméstico, quer industrial".

Desta forma, a degradação da qualidade da água pode conduzir à impossibilidade da sua utilização, obrigando a um abastecimento alternativo ou, por outro lado, encarecer os processos de depuração utilizados. Situações particularmente graves, de contaminação de águas subterrâneas, podem ocorrer na sequência do abandono de minas subterrâneas. Nestes casos, com o alagamento progressivo das galerias, o nível freático restabelece-se a cotas próximas das originais, pelo que as captações existentes na área envolvente podem ficar contaminadas.

GonzÁlez (1990: 312) acrescenta que "os sulfuretos existentes nos jazigos mineiros dão origem ao surgimento de ácidos e compostos químicos que afetam, sucessivamente, as águas, os solos, a fauna, a flora, e, finalmente o Homem e a paisagem". Segundo ÁvILA et al., (2008) pode observar-se que alguns dos sedimentos da ribeira do Bodelhão, estão seriamente contaminados em relação ao nível dos sedimentos (valores obtidos a partir de amostras colhidas numa área a montante não afectada pela mina), apesar de existir alguma mitigação após a confluência com o Rio Zêzere. Comparando

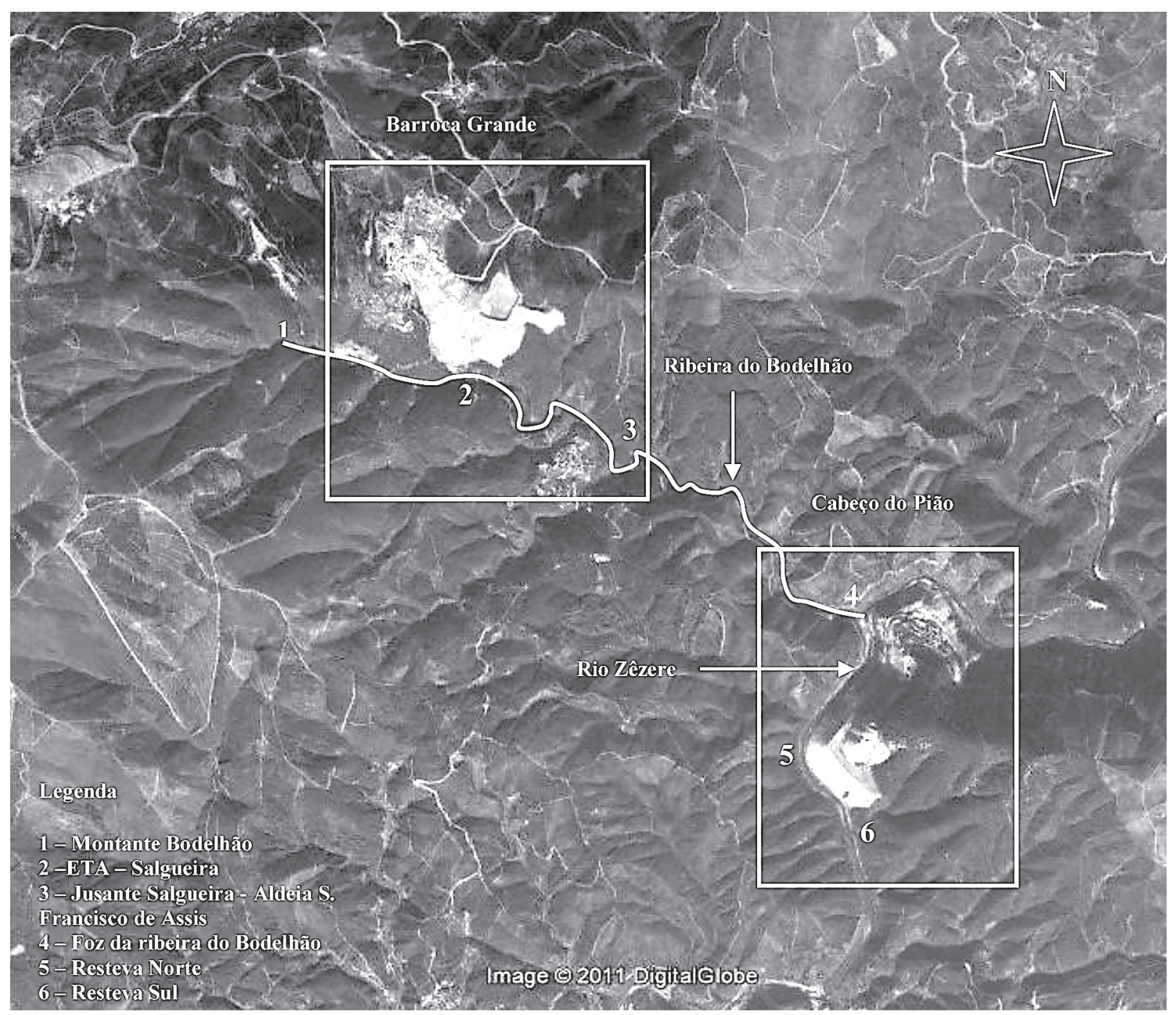

Figura 2

Locais onde foram recolhidas as amostras referidas em ÁviLA, 2008 e GonCALVES 1995/2010 
os valores médios da ribeira do Bodelhão e Zêzere, com os valores médios de sedimentos de fundo, é claro que a contaminação vai de moderada a forte em função dos metais encontrados (Cádmio, Cobre e Zinco).

Tendo em conta a toxicidade destes elementos, isto representa uma situação potencialmente prejudicial.

Assim, os valores de contaminação estimados para os sedimentos são elevados na ribeira do Bodelhão e rio Zêzere (Figura 2), em função das diretrizes de qualidade de sedimentos aquáticos de Ontário (Persaud et al., 1993, in ÁvILA, 2008) a maioria das amostras da ribeira do Bodelhão, excede o efeito considerado para o Cu (100\% de amostras), Cd (90\% das amostras) e Zn (50\% de amostras) sendo assim considerados 'grosseiramente poluídos'.

A mesma autora (o. c; 2008) confirma que as amostras de sedimentos recolhidos no rio a jusante da escombreira do Cabeço do Pião, após a confluência da ribeira do Bodelhão com o rio Zêzere, contêm volframite, cassiterite, mica, quartzo, feldspato, clorito-vermiculite e hematite. Estes minerais são típicos da mineralização local e confirmam que a contaminação da ribeira do Bodelhão e do rio Zêzere, é devida ao lançamento direto e indireto de resíduos das minas nas ribeiras e rios locais.

Ao longo do ano de 2010, recolhemos amostras (conjuntamente com os técnicos do laboratório da S.B.T.W.P.) nas águas do rio Zêzere, junto à escombreira do Cabeço do Pião (Figura 2), para determinar os teores dos metais dissolvidos para os meses de 2010, estes apresentavam valores que deram origem aos gráficos abaixo.

Da análise dos dados e gráficos referidos, verifica-se que é no período do verão com baixa ou nula queda pluviométrica que se observam os valores mais baixos de pH, exceção feita na ETA - Estação de Tratamento de Águas da Salgueira, onde o pH sobe para valores superiores a 7 , em virtude do tratamento efe-

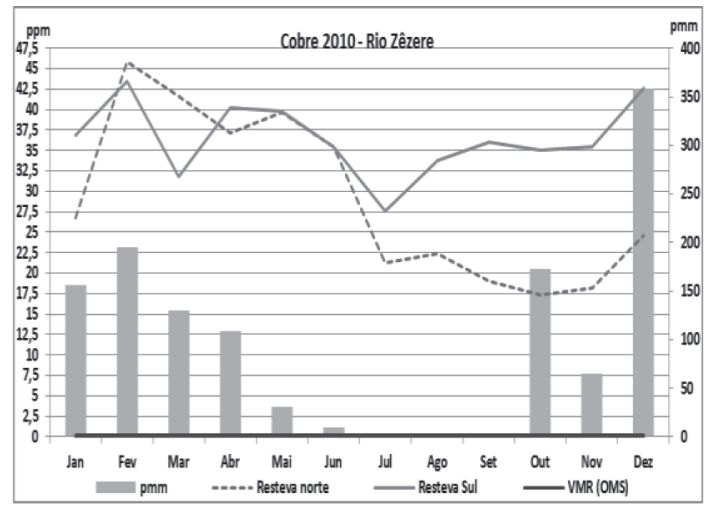

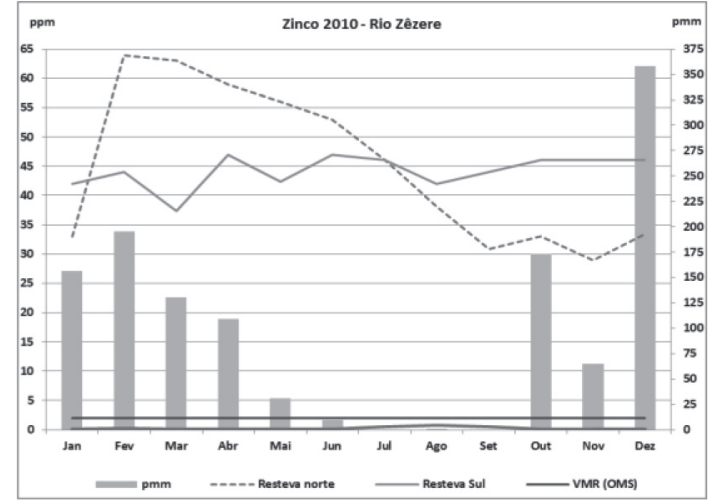
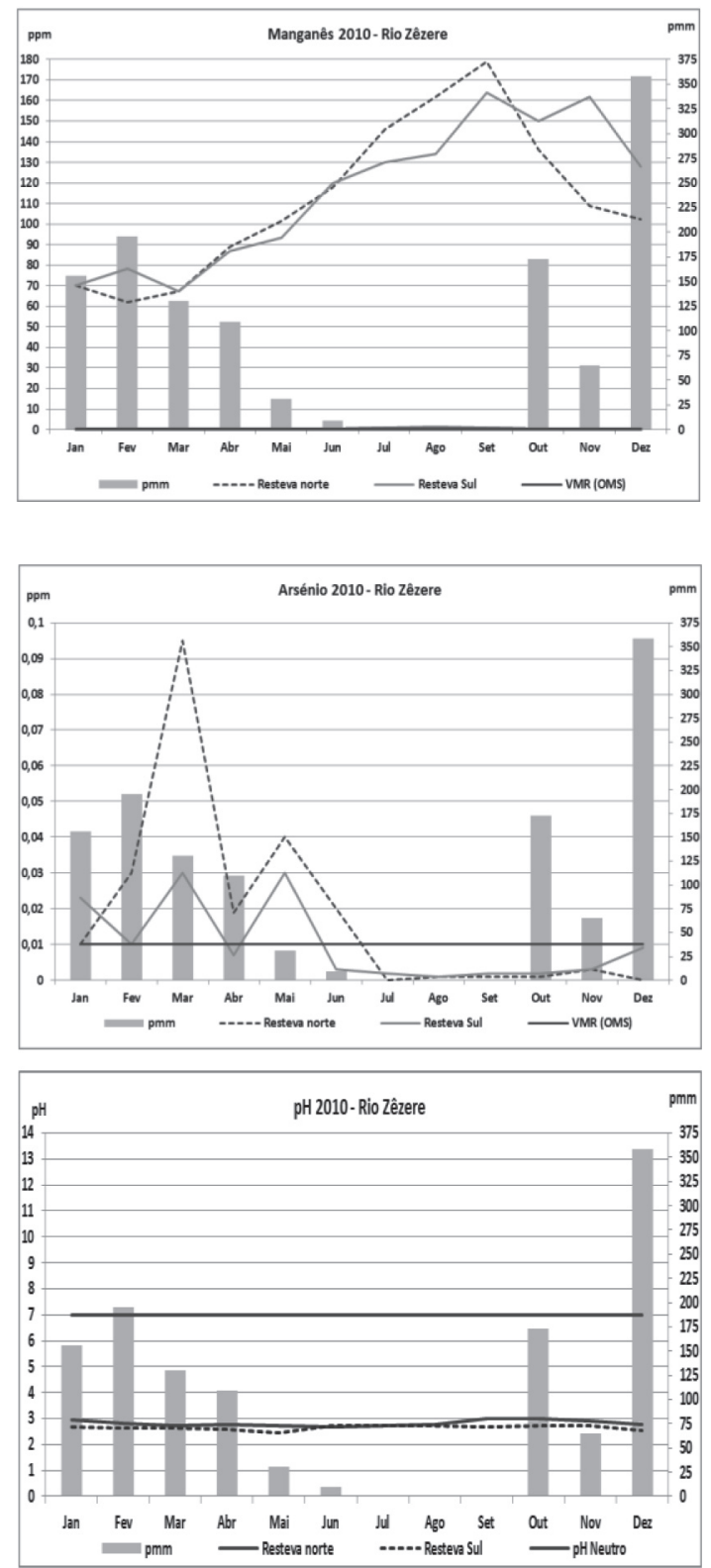

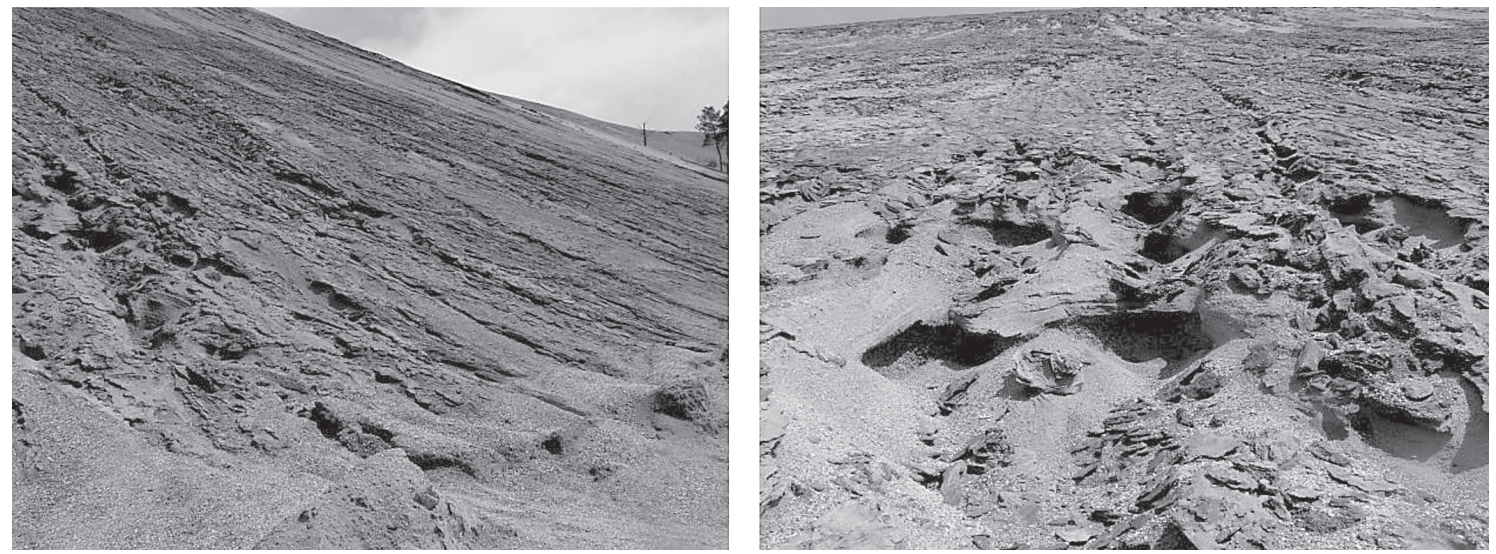

\section{Fotografia 3}

A escombreira do Cabeço do Pião apresenta um aumento dos ravinamentos em função do ataque da água escorrencial à carapaça ferruginosa que a cobre, denota-se tal situação derivado ao abandono da manutenção desta escombreira desde 1995

(Fotografias do Autor, 30.03.2011).

tuado com cal (que se mostra ineficaz). No entanto, cerca de $2 \mathrm{~km}$ a jusante deste local, no ponto de recotha denominado ribeira do Bodelhão, os valores voltam a situar-se entre os 4,9 e os 6 , estamos em crer que a jusante da ETA da Salgueira existem escoamentos a partir da escombreira que suporta a barragem de lamas que desembocam sem qualquer tratamento na ribeira do Bodelhão, contribuindo de forma decisiva para baixar o $\mathrm{pH}$, impondo um aumento dos teores dos metais pesados na água da ribeira. No rio Zêzere, nos locais de recolha Resteva Norte e Resteva Sul os valores mantêm-se sempre muito baixos (2,5 a 3), independentemente dos períodos com maior ou menor precipitação.

As maiores concentrações de metais pesados em suspensão ( $\mathrm{Cu}, \mathrm{Zn}, \mathrm{Mn}$ e $\mathrm{As}$ ), encontrados ao longo de 2010, ocorrem no rio Zêzere nos pontos de recolha denominados de Resteva Norte e Resteva Sul (a jusante da foz da ribeira do Bodelhão), exatamente no local onde se encontra a barragem de lamas desativada desde 1994 no Cabeço do Pião, indo as escorrências com os metais pesados directamente para o rio Zêzere sem qualquer tratamento e disseminando-se na corrente.

Segundo Machado (1994) é "durante o inverno, com maior quantidade de precipitação e o consequente aumento dos caudais dos cursos de água já referidos, o efeito da diluição faz de alguma forma reduzir as concentrações de metais, aumentando ligeiramente os valores de $\mathrm{pH}$ ". É de realçar que na maioria das análises efetuadas foram, em quase todas, ultrapassados os valores máximos recomendáveis pela OMS.

Não totalmente de acordo com MACHADO (1994), que aponta como justificação para valores mais baixos de concentrações de metais pesados, a intensa queda de precipitação ocorrida meses antes da recolha da amostra contribuía para que a diluição destes fosse mais rápida, depreendendo a autora que tal situação poderia sofrer profunda alteração em época de estiagem quando a quantidade de água diminuir no canal do rio e, portanto, o efeito da diluição não ser tão evidente. Pelo contrário pudemos verificar que, em períodos de queda pluviométrica constante e ao longo de vários dias, não diminui a concentração de metais pesados em suspensão, pelo contrário, esta concentração aumenta. Esta situação deve-se ao efeito da percolação e de lavagem escorrencial, que provoca um ataque erosivo às escombreiras dando origem à formação de ravinas (Fotografia 3) e portanto, os materiais carreados são encaminhados invariavelmente para a ribeira do Bodelhão e para o rio Zêzere, aumentando os teores dos metais analisados em suspensão, casos do Cobre, Manganês e Arsénio, nos meses de Janeiro, Fevereiro, Março e Dezembro, conforme se pode verificar nos gráficos.

Também CRESPO (2006) evidencia a elevada necessidade de todas as águas provenientes da mina serem de fato tratadas em ETAR, o que já é efetuado desde 1957 , mas apenas para caudais na ordem de $300 \mathrm{~m}^{3} / \mathrm{h}$, segundo o autor, não é suficiente visto que estes podem

Quadro I

Classificação segundo White (1968) dos efluentes gerados pelas atividades mineiras

\begin{tabular}{|l|c|}
\hline \multicolumn{1}{|c|}{ Classes } & $\mathrm{pH}$ \\
\hline 1 - Altamente ácidos & 1,5 a 4,5 \\
\hline 2 - Brandos, ligeiramente ácidos & 5,0 a 7,0 \\
\hline 3 - Duros, neutros a alcalinos & 7,0 a 8,5 \\
\hline 4 - Brandos, alcalinos & 7,5 a 11,0 \\
\hline
\end{tabular}

Fonte: ITGE, 1989 


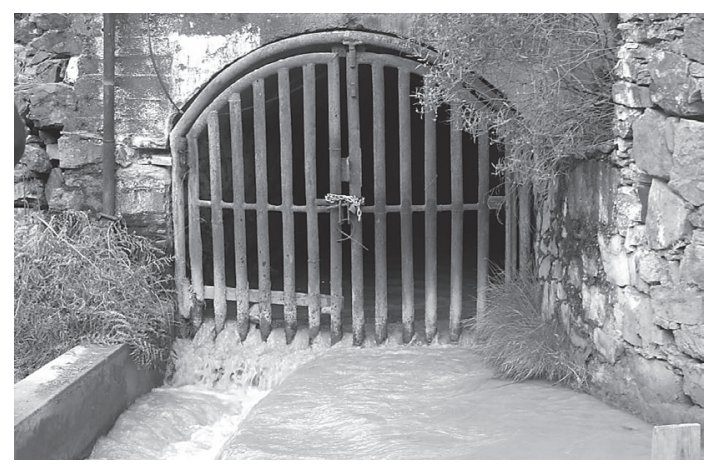

Fotografia 4

Saída da água da mina, antes da ETAR da Salgueira

(Fotografia do Autor, 30.03.2011).

chegar a valores superiores a $1000 \mathrm{~m}^{3} / \mathrm{h}$ durante o Inverno, criando sérios problemas aos ribeiros e aos rios que os recebem, no caso o Zêzere. Associado a este problema surge a elevada acidez da água à saída da mina (Fotografia 4) que apresenta um pH médio abaixo de 4,1, o que as insere na classe de altamente ácidas de acordo com o Quadro I.

No entanto em áreas mineiras abandonadas o risco consiste na eventualidade de contaminação das águas devido à descarga direta de efluentes gerados na mina e desta para as linhas de água e, à infiltração de poluentes nos aquíferos.

As plantas e os animais, por dependerem das condições dos solos e da água, podem ser atingidos por não conseguirem suportar as condições de acidez e toxicidade. A existência de vegetação espontânea autóctone pode ser mesmo fortemente atingida ou mesmo destruída pela toxicidade inerente a certos teores de metais pesados, quer pela excessiva acidez do substrato que pode interferir na disponibilidade de nutrientes essen-

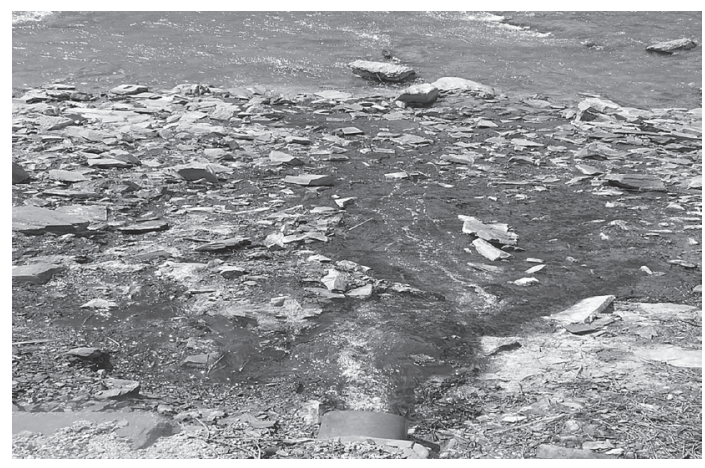

\section{Fotografia 5}

Local da colheita na Resteva Sul denuncia a existência da alga Microspora Tumidula Hazen, confirmam a elevada acumulação de arsénio (ÁVILA, 2010)

(Fotografia Autor, 30.03.2011). ciais (ITGE, 1989). Em escombreiras, a parte mais problemática coincide com a parte mais superficial destas, onde se podem registar os valores mais baixos de $\mathrm{pH}$ (RuBı et al., 1986), como podemos inferir dos dados dos gráficos referentes ao rio Zêzere, nos locais de análise Resteva Norte e Resteva Sul, no Cabeço do Pião, onde os valores de $\mathrm{pH}$ da última colheita por nós efetuada (30.03.2011), apontam para valores de 2,69 e 2,48, respetivamente.

A absorção e acumulação dos metais pela biota ${ }^{2}$ a partir dos sedimentos é significativa no que diz respeito ao Cobre, Zinco e Arsénio.

Além das drenagens ácidas, a disseminação de contaminantes a partir dos materiais depositados nas escombreiras também pode ser processado devido aos fenómenos erosivos (hídrica e eólica) e aos deslizamentos de massa, que contribuem para o carrear de partículas das escombreiras para as linhas de água e terrenos circundantes (Fotografia 6).

OJEA (1995: 87) para idêntica situação à da Panasqueira, aponta efeitos devido à falta de coesão dos estéreis a ver: a ação do vento em época de seca provoca a formação de nuvens de pó e em épocas de elevada queda de precipitação, através da escorrência superficial, cuja ação erosiva é potenciada pela presença de declives elevados ${ }^{3}$, surgem ravinas (Fotografia 4) que se vão intensificando e que nesta situação não se devem exclusivamente à ação natural mas também à acção antrópica. Nessa perspetiva Rebelo (1994: 10) aponta para situações complicadas nas imediações das minas, chamando à atenção que em "climas como os nossos, podem originar problemas graves de movimentações em massa ou fornecem muito material sem coesão para movimentações individuais em ravinas que entretanto se formem, uma vez que, em regra, não é fácil a sua fixação natural pelas espécies vegetais mais frequentes".

\section{Riscos internos}

Nas explorações subterrâneas há vários riscos que são coincidentes, no entanto, pelo conhecimento pessoal da mina da Panasqueira, podemos elencar alguns, entre eles os desabamentos e queda de blocos em

${ }^{2}$ Biota - é o conjunto de seres vivos de um ecossistema, o que inclui a flora, a fauna, os fungos e outros grupos de organismos

${ }^{3}$ A. R. CoRdeiro (2004: 358) realça que "ao passar a existir um declive claro, este, em associação com os fatores ligados aos agentes meteóricos, vai provocar o desencadeamento da ação erosiva, tornando-se esta mais intensa à medida que o declive se torna maior, e isto, quaisquer que sejam os restantes fatores". 

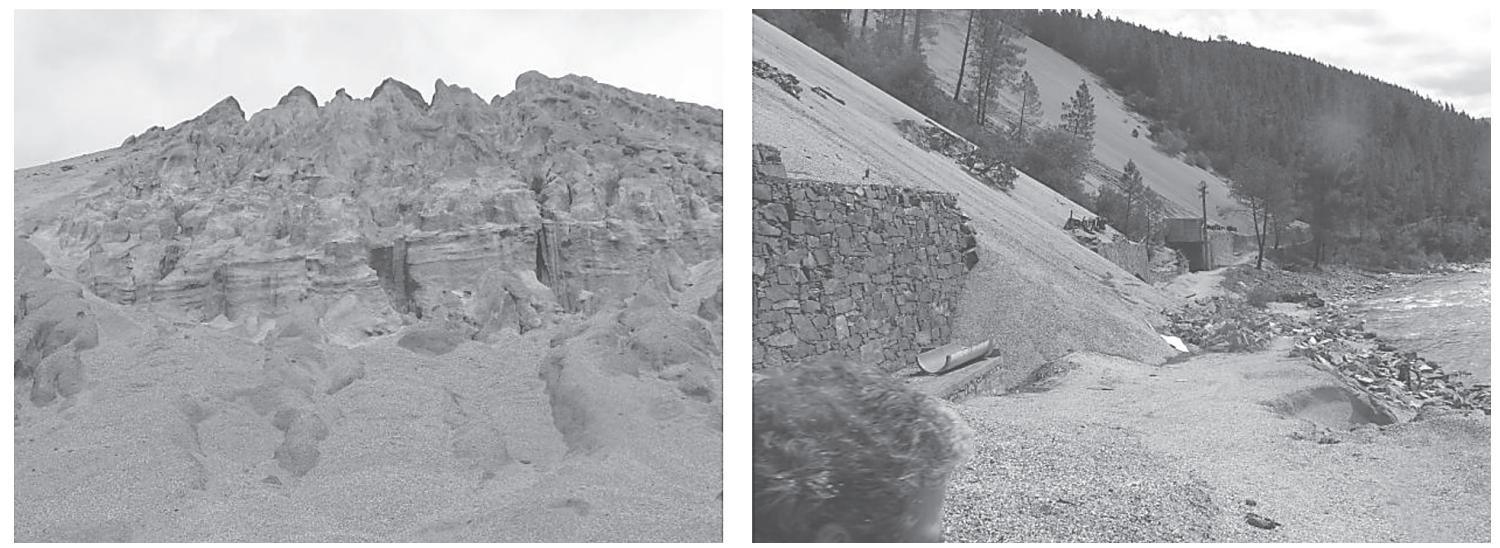

\section{Fotografia 6}

Ravinamentos instalados e um fluxo de detritos recente que quebrou o muro de suporte em betão e pedra na escombreira abandonada do Cabeço Pião. Podese verificar que o rio Zêzere corre mesmo ao lado.

(Fotografias Autor, 30.03.2011)

minas subterrâneas constituem um risco, quer no subsolo, quer à superfície.

À superfície podem ocorrer subsidências como resultado natural da extração subterrânea. A extração de material em profundidade induz uma maior compactação das rochas face à pressão litoestática sobrejacente, conduzindo à ocorrência de planos de deslocamento que afloram à superfície do terreno, resultando em movimentos verticais e consequentes deformações na superfície. Segundo o ITGE (1989), os movimentos de subsidência são controlados por dois grupos de fatores: geológicos, que têm a ver com características litológicas da área explorada, e mineiros, que tem a ver com os métodos de exploração e profundidade alcançada pelos trabalhos. 0 colapso de chaminés e galerias pode provocar depressões topográficas e cavidades no terreno, causando dessa forma danos às estruturas superficiais tais como: edifícios, rede de distribuição de água, saneamento básico, caminhos, etc.

No interior da mina ocorrem com muita frequência, acidentes fatais provocados pela queda ou desabamento de rochas, "lisos". Esta instabilidade depende de factores associados às propriedades geomecânicas e geotécnicas do maciço rochoso, à forma e tamanho da abertura, profundidade a que a exploração se encontra e método construtivo utilizado. Infelizmente é esta situação a causa de duas das três últimas mortes ocorridas nas minas da Panasqueira, em 2006 e 2011. No interior de uma mina deve-se, em cada momento, estar preparado para a queda de "lisos", que podem provocar um acidente grave ou mesmo a morte. A força da gravidade está permanentemente a trabalhar contra os mineiros. BienIAWSKI (1992) in Gama (2005), refere que, estes desabamentos (que na linguagem local se designam "queda de lisos") têm a ver com a ação da gravidade, pressão da água e tensões in-situ, já Hudson in GAMA (2005) relaciona-os com a influência da percolação da água e das falhas.

- Os incêndios dentro da mina da Panasqueira, não são habituais, mas podem ocorrer tendo em conta que se executam no seu interior trabalhos de soldadura em veículos motorizados, em instalações eléctricas (tendo recentemente ocorrido um acidente grave com um electricista que procedia a reparações do sistema) e, em correias transportadoras. Estes incêndios, embora podendo ser de pequena dimensão, produzem, no entanto, elevada quantidade de fumos tóxicos que podem comprometer drasticamente a qualidade do ar colocando em risco a qualidade do ar no interior da mina e por consequência os mineiros.

- Dentro da mina os riscos associados à circulação intensa de uma multiplicidade de veículos têm a ver com atropelamentos (por ausência de coletes refletores), choques de veículos, quedas dos maquinistas, falhas de manutenção e desgaste dos veículos, etc.

- As operações de manipulação de explosivos, apenas devem ser efectuadas por pessoal devidamente preparado e autorizado para tal. Os riscos gerados neste trabalho estão presentes em toda a operação desde o armazenamento, transporte, preparação de cargas a utilizar, até à eliminação dos restos de explosivos. Todos os trabalhadores que manipulam os explosivos 
devem estar preparados para resolver todas as situações anormais que possam vir a suceder.

\subsection{Acidentes de trabalho}

No que aos acidentes de trabalho diz respeito, um estudo efetuado pela empresa em 2007, executado pelo departamento de Higiene e Segurança no Trabalho desta, foi o consumo excessivo de álcool considerado o principal causador dos acidentes mais graves, desde mortes, lesões causadoras de incapacidade total (amputações de membros superiores e inferiores) e parcial, para o trabalho na mina (perda de dedos de mãos e pés), assim como incapacidades temporárias de longa duração (pernas e braços partidos, lesões de foro ortopédico entorses, roturas, tuberculose associada a deficiente alimentação e consumo excessivo de tabaco e de álcool $\left.{ }^{4}\right)$.

Nesse sentido, a empresa, desenvolveu uma nova forma de abordar o problema que afetou durante muitos anos a produtividade. Para além de uma substancial aposta na informação e formação dos mineiros, é hoje feita uma triagem de alcoolémia aos mesmos nas entradas da mina às $7 \mathrm{H}, 15 \mathrm{H}$ e $23 \mathrm{H}$ e os trabalhadores que apresentam um nível superior ao definido por lei são enviados para casa, com recomendação de não voltarem a apresentar aqueles níveis de futuro. No caso de reincidir é aplicada a sanção "porro", de dois a cinco dias em casa sem poder entrar na empresa e com perda de salário correspondente. Se o mineiro não alterar o comportamento de risco, é considerada a possibilidade de despedimento com justa causa (circular interna, 2007).

A maneira como a empresa está a atacar o problema parece estar a ter sucesso, que, diga-se, tem tido da parte dos mineiros uma adesão que é preciso referir, fazendo com que o número de acidentes de trabalho tenha sido fortemente reduzido. Em início de Julho de 2012, a empresa registava 180 dias sem qualquer tipo de acidente. Ainda a referir que a empresa tem desenvolvido um forte apelo junto de todos os mineiros no sentido de estes usarem todos os equipamentos de segurança pessoal que thes são atribuídos no caso: capacetes, luvas, botas protetoras e máscaras para os mineiros que contactam diretamente com os desmontes. Para nós é também uma prioridade no que aos acidentes de trabalho diz respeito, pois por diversas vezes em

${ }^{4}$ Questionei alguns mineiros sobre esta situação à qual responderam que, o álcool muitas das vezes funciona como algo que thes retira o medo, pois dizem, sem ele não tinham coragem de ir para sítios que nenhum homem quereria ir. Os mineiros mais velhos afirmam que o seu consumo baseia-se em aguardente, que dizem, limpa os pulmões. Crenças que vêm de um passado distante da exploração mineira. visitas ao interior da mina vimos mineiros sem luvas, por vezes sem o capacete (sabemos que alguns equipamentos de segurança pessoal geram desconforto e retiram sensibilidade ao mineiro), no entanto, a utilização destes equipamentos, pode marcar a diferença entre um trabalho em segurança ou um acidente de trabalho que pode impedir o mineiro de laborar durante várias semanas.

\subsection{Riscos para a saúde em ambiente mineiro}

"Alguns, já nem sangue têm: foram-no cuspindo pela boca, arrombados de todo..." Daniel Rels e Fernando Paulouro (1979: 11)

Muitos dos impactes negativos que ocorrem pelo funcionamento de uma exploração mineira, incidem direta ou indiretamente sobre o Homem e suas comunidades. Para a Panasqueira e no que toca a este tema nada está escrito nem trabalhado, afigura-se-nos algo tabu, atendendo a, que ao longo dos seus 116 anos de actividade quase ininterrupta, provocou direta e indiretamente um número considerável de mortos pela ação de acidentes de trabalho, silicose, tuberculose e outros efeitos ligados ao ruído, que deixaram marcas na qualidade de vida dos mineiros que se tornaram irrecuperáveis. De uma forma sucinta, elencaremos algumas ideias relativas a esta temática.

1 - Os mineiros estão sujeitos a acidentes e a doenças profissionais (silicose, neoplasias no pulmão, bronquites crónicas, surdez). OLIVEIRA e ÁvILA (1995), advertem para a possibilidade de existência de contaminações químicas, que são resultantes da alteração dos minerais da escombreira e do interior da própria mina, bem como do arrastamento de poeiras finas pela ação do vento.

Nesse sentido, as poeiras geradas no processo de desmonte das frentes de exploração, ao longo do transporte do material extraído, na fase do tratamento e estilhaçamento do minério e no transporte e deposição do estéril na escombreira, assim como fumos, vapores e gazes (dióxido de azoto, dióxido de enxofre, monóxido e dióxido de carbono) que são gerados em todo o processo de extração do minério, são essencialmente produzidos pelo funcionamento de veículos e equipamentos pesados (ITGE, 1989; ValCARLos, 1993), geram quantidades elevadas de poeiras que interferem na qualidade do ar respirável, podendo criar danos na saúde pública e daqueles que diariamente convivem com estas poeiras que são em especial os mineiros e toda a população que reside em áreas limítrofes à exploração, 
L. BARros (1983) chamava à atenção para uma exposição mais ou menos prolongada a poeiras muito finas de sílica poder provocar a fibrose nodular pulmonar, mais conhecida por silicose ${ }^{5}$, ao mesmo tempo alertava para que, em ambientes mineiros muitas das poeiras que são inaladas, são potencialmente indutoras de carcinomas por serem compostas por minerais potenciadores dessas situações (Quadro II).

Quadro II

Efeitos da poluição atmosférica exterior

$$
\begin{aligned}
& \text { - Morte } \\
& \text { - Cancro do pulmão } \\
& \text { - Bronquite crónica } \\
& \text { - Inflamação } \\
& \text { - Modificação temporária da função respiratória } \\
& \text { - Incomodo } \\
& \text { - Irritação das mucosas dos olhos }
\end{aligned}
$$

(Adaptado RYLANDER et al., 1993)

Recentemente Gomes (2010), chamou a atenção para uma exposição excessiva a poeiras respiráveis de origem natural ou em explorações mineiras, que contêm certos minerais tais como sílica cristalina, arsenopirite e manganês ${ }^{6}$ (todos em elevada concentração na exploração mineira da Panasqueira), considerando-as potencialmente tóxicas.

Não podemos esquecer que atualmente, a tendência da mecanização das minas subterrâneas conduz a uma intensa utilização de equipamentos com motor a diesel, como são os jumbos para perfuração, as pás (LHDs) para remoção do mineral na frente de trabalho, os camiões (dumpers) e outras máquinas como as locomotivas que além de emitirem gases tóxicos, geram partículas em forma de fuligem que são respiradas pe-

${ }^{5}$ Segundo Gomes (2010) "A silicose é uma forma de pneumoconiose causada pela inalação de partículas finas de sílica cristalina. É uma pneumoconiose que afeta os pulmões através do desenvolvimento de nódulos fibrosos. A silicose enquanto doença pode levar até 20 anos para ser detetada radiograficamente. A O.M.S., registou a sílica cristalina como material carcinogénico nos seres humanos. Os sintomas da silicose manifestamse por dificuldade respiratória (dispneia) e debilidade física (astenia).

${ }^{6} \mathrm{~A}$ arsenicose é uma doença atribuída ao contacto ou ingestão de arsénio que ocorre disperso noutros minerais particularmente sulfuretos do tipo pirite e arsenopirite. A sua forma de incorporação no corpo humano, ocorre através da inalação de ar e água poluída portadora de arsénio. Tchounwou et al., 2004 in Gomes, (2010), alerta para que a exposição ao Arsénio e seus compostos pode causar mutações celulares e carcinogénese ao nível da pele, pulmão, bexiga, rim e fígado. A ingestão de água contaminada causa afeções de pele e alteração da pigmentação (melanose). HopenhaYn, 2006, in Gomes, 2010, alerta ainda para que o Arsénio surge ainda ligado a certos tipos de cancro, diabetes, doenças vasculares, hipertensão e desordens neurológicas.

0 manganismo é doença considerada letal e atribuída ao envenenamento pelo manganês, devido à inalação da poeira mineral pelos mineiros que trabalham em explorações onde este mineral existe em grandes quantidades ou associado. 0 principal sintoma da doença que ataca o cérebro é idêntico à doença de Parkinson (Nel et al., 1986 in GOMEs, 2010). los mineiros. Estas partículas contêm produtos cancerígenos que se acumulam nos pulmões.

Associado a este problema surge, no ambiente subterrâneo, o ruído que tem a ver com as atividades operacionais tais como perfuração ou corte, disparos ou desmonte, carregamento, transporte extracção, ventilação, bombagem, britagem, etc. Ao fim de algum tempo de exposição, os mineiros começam a apresentar crescente perda de audição que ao longo da vida ativa pode levar à perda total da audição, é comum queixarem-se de fortes dores de cabeça, fadiga, distúrbios cardiovasculares, alterações hormonais, gastrites, dis função digestiva, alergias, isto no plano físico, já no plano psicológico dá-se uma perda de concentração, perda de reflexos, irritação permanente, insegurança quanto à eficiência dos atos, perda da inteligibilidade das palavras, o que poderá contribuir para um aumento de acidentes de trabalho (Gama, 2005).

2 - As comunidades envolventes estão, também sujeitas aos efeitos do ruído das máquinas, rebentamentos e consequentes vibrações do solo, emissões de gases e poeiras, assim como da contaminação dos solos e das águas superficiais e subterrâneas que impedem a prática da agricultura e das regas, além das águas de consumo humano estarem contaminadas.

BARRos (1983) apontava para uma acção nefasta dos elementos químicos que, quando concentrados no solo, plantas ou ainda transportados pelas águas podem ter acções nefastas sobre os animais e em especial sobre o Homem (Quadro III).

Estamos a lembrar-nos das comunidades locais como a da Panasqueira, Barroca Grande, Aldeia de S. Francisco de Assis e do Cabeço do Pião, pela sua proximidade assim como fazerem parte dessas mesmas es combreiras, e das ribeiras de Cebola, Porsim e Bodelhão e do rio Zêzere que, quer no passado, quer no presente, continuam severamente contaminados.

Neste aspecto, atribuímos significativa influência das escombreiras na saúde pública que, segundo RyLAN-

Quadro III

Efeitos na saúde do Homem pela água poluída com metais pesados

\begin{tabular}{|l|l|}
\hline \multicolumn{1}{|c|}{ Poluente } & \multicolumn{1}{c|}{ Efeitos para a saúde } \\
\hline Cobre $(\mathrm{Cu})$ & Moléstias de estômago e intestinos, doença de Wilson \\
\hline Zinco $(\mathrm{Zn})$ & $\begin{array}{l}\text { A inalação de óxido de zinco pode provocar lesões nos } \\
\text { pulmões e, de um modo geral, em todo o sistema res- } \\
\text { piratório }\end{array}$ \\
\hline Ferro $(\mathrm{Fe})$ & Anorexia, tonturas, fadiga e dores de cabeça \\
\hline Manganésio $(\mathrm{Mn})$ & $\begin{array}{l}\text { Inalado ou ingerido, pode provocar efeitos adversos no } \\
\text { sistema nervoso, respiratório e outros. }\end{array}$ \\
\hline Arsénio (As) & $\begin{array}{l}\text { Tóxico, dermatológico e afecta o sistema nervoso, é } \\
\text { carcinógeno }\end{array}$ \\
\hline
\end{tabular}

(Adaptado de KIELY citado por GAMA, 2005) 
DER et al., (1995), se estas estiverem sem qualquer tipo de tratamento ou manutenção provocam às populações mais afastadas lesões / perturbações que não sendo visíveis de imediato, vão ter efeitos que se irão manifestar mais tarde, já que estas estão praticamente no perímetro urbano dessas aldeias. Segundo RYLANDER et al., (1995), o efeito combinado de alguns factores meteorológicos e a presença de poluição (neste caso grandes quantidades de poeiras muito finas) são favorecedoras de sintomatologia irritativa para as mucosas do nariz e olhos, podendo também afectar temporariamente a função respiratória (Quadro 2).

\section{Conclusão}

Concluímos esta reflexão dando a conhecer o despacho de 11 de Maio de 2006 da autoria do então Ministro do Ambiente do Ordenamento do Território e do Desenvolvimento Regional, Prof. Doutor Eng ${ }^{\circ}$ Francisco Nunes Correia, considerava então que "as escombreiras e a barragem de lamas do Cabeço do Pião, sendo constituídas por materiais finos e metais pesados, apresentam níveis elevados de toxicidade, associados a sinais graves de instabilidade que podem colocar em risco a segurança de pessoas e bens, e são perigosas para o ambiente e para a saúde pública, em particular no que concerne a uma possível contaminação das águas do rio Zêzere”. Deste despacho foi dado conhecimento aos Ministros da Administração Interna, Ministro da Economia e Inovação, Ministro das Obras Públicas, Transportes e Comunicações e à Governadora Civil do distrito de Castelo Branco.

Existe preocupação, ela circula sobre a forma de circulares, circulares internas, portarias, despachos, notas informativas, mas sempre e só dentro de gabinetes. É nossa preocupação com este texto, dar a conhecer aos interessados os riscos associados à indústria mineira para que as comunidades que estão inseridas nesses espaços ou em áreas envolventes assumam de uma forma consciente a gestão do risco a que estão expostos, exigindo das autoridades competentes um maior acompanhamento, e proteção.

\section{Bibliografia}

Ávila, Paula; SILVA, Eduardo; Salguelro, Ana e Farinha, J. (2008) "Geochemistry and Mineralogy of Mill Tailings Impoundments from the Panasqueira Mine (Portugal):
Implications for the Surrounding Environment". Mine Water Environ, 27, pp. 210-224

ÁviLA, Paula (2010) - "Visita à mina de Vale de Gatas. Notas para a excursão de Geoquímica Ambiental em áreas mineiras abandonadas do norte de Portugal". Atas do X Congresso de Geoquímica dos Países de Língua Portuguesa - XVI Semana de Geoquímica.

Barros, Luís Aires (1983) - "Os minerais e as suas eventuais acções agressivas sobre o organismo humano". Bol. Minas, 20 (2) Abr./ Jun., Lisboa, pp. 67-76

Cordeiro, António R. (2004) - Dinâmica de Vertentes em Montanhas Ocidentais do Portugal Central. Dissertação de Doutoramento em Letras na Área de Geografia especialidade de Geografia apresentada à Faculdade de Letras da Universidade de Coimbra, 561 p.+ Esboço Geomorfológico.

COSTA, Luís Rodrigues (2000) - "Indústria mineira: integração ou conflito?" Boletim de Minas, 37 (1), IGM. Lisboa, pp. 3-20

CRESPO, Eduardo Vilhena (2006) - "Renovação da ETAR da Salgueira". Nota Técnica interna, B.T.W.P

Favas, Paulo Jorge de Campos (1999) - Impacte Ambiental de Minas Abandonadas. O exemplo das Minas de Vale de Gatas (Sabrosa - Vila Real). Dissertação de Mestrado em Geociências área de especialização em Ambiente e Ordenamento do Território, apresentada ao D.C.T da FCTUC.

Gama, Carlos Dinis da e Torres, Vidal Felix Navarro (2005) Engenharia ambiental subterrânea e aplicações. Cetem / Cyted, Rio de Janeiro, 542 p.

Gomes, C. S. F. e Silva, J. B. P. (2010) - "Impactes Negativos de Minerais e Ambientes Geológicos na Saúde Humana". In: Ciências Geológicas - Ensino e Investigação e sua História, Vol. II, Capítulo II - Geologia e Ambiente. Lisboa, pp. 219-228.

Gonçalves, Anselmo C. Ramos (2007) - Mina da panasqueira contributo para um plano de recuperação ambiental $e$ paisagística. Dissertação de Mestrado em Geografia especialização em Geografia Física e Estudos Ambientais, apresentada à Faculdade de Letras da Universidade de Coimbra.

Gonçalves, Anselmo C. Ramos (2010) - "Impactes Ambientais em Áreas Mineiras Activas - O Caso da Ribeira do Bodelhão Minas da Panasqueira". Atas do VI Seminário LatinoAmericano de Geografia Física. II Seminário IberoAmericano de Geografia Física Universidade de Coimbra, Maio de 2010 em: www.uc.pt/fluc/cegot/VISLAGF/ actas/tema4/anselmo

GonçALVES, Anselmo C. Ramos (2011) - "Alterações Ambientais Recentes e Riscos Associados no Médio Curso do Rio Zêzere - O Couto Mineiro da Panasqueira". In: SANTOS, N 
e CunHa, L. (coord.) - Trunfos de Uma Geografia Activa. Desenvolvimento Local, Ambiente, Ordenamento $e$ Tecnologia. Imprensa da Universidade de Coimbra, pp. 753-760

González, Victor (1990) - "A Indústria Extractiva e o Ambiente". Boletim de Minas, 27 (3), Lisboa, pp. 311-323

Guidicinl, Guido e Nieble, Carlos (2003) - Estabilidade de taludes naturais e de escavação. 2a Edição, Editora Edgar Blucher, São Paulo.

ITGE (1989) - Manual de restauracion de terrenos y evaluacion de impactos ambientales em mineria. Série: Ingeneria GeoAmbiental, Ministério de Industria y Energia, Madrid.

MACHADo, Maria José do Canto (1994) - "Impacto Ambiental das Minas da Panasqueira na Bacia Hidrográfica do Rio Zêzere. Contribuição para um estudo". Relatório Interno do I.G.M, Lisboa.

OJeA, Francisco Guitián (Coord.) (1995) - Recuperación de las escombreras de la mina de lignitos de Meirama (A Coruña). Universidade de Santiago de Compostela.

Olivelra, J. e Ávila, Paula (1995) - "Avaliação do Impacto Químico Ambiental Provocado por Uma Exploração Mineira. Um
Caso de estudo na Mina de Jales". Estudos, Notas e Trabalhos do IGM, 37, Lisboa, pp. 25-50

Pagés Valcarlos, J. L. (1993) - "Las Alteracciones ambientales en sistemas naturales provocadas por la minería metálica". Cuaderno Lab.Xeolóxico de Laxe, Vol. 18, pp. 289-306

PIno, Erick (2002) - Riesgos en la Minería Subterránea. Servício Nacional de Geologia y Minería, Gobierno de Chile.

Rebelo, Fernando (1994) - "Do ordenamento do território à gestão dos riscos naturais. A importância da Geografia Física salientada através de casos de estudo seleccionados em Portugal”. Territorium, 1, Coimbra, pp. 7-15

ReIS, Daniel e Paulouro, Fernando (1979) - A guerra da mina e os mineiros da panasqueira. A Regra do Jogo Edições, Lisboa.

Roque, Magda Cristina (2009) - Estudos de Caracterização de Áreas Mineiras Degradadas. Proposta de Metodologia com Aplicação à Área Mineira de Santo António, Penedono. Dissertação de doutoramento apresentada ao Dept $^{\circ}$ de Geologia Faculdade de Ciências da Universidade de Lisboa, $400 \mathrm{p}+$ Anexos.

Rylander, R. e Megevand, I. (1993) - Introdução à Medicina do Ambiente. Instituto Piaget, Lisboa. 